\title{
Metodologia 7Cs: Uma Nova Proposta de Aprendizagem para a Disciplina Algoritmos
}

\author{
Árllon Chaves Lima ${ }^{1,2}$, Marcos Monteiro Diniz ${ }^{1,2}$, Marianne Kogut Eliasquevici ${ }^{1,2}$ \\ ${ }^{1}$ Núcleo de Inovação e Tecnologias Aplicadas a Ensino e Extensão (NITAE²)
}

${ }^{2}$ Programa de Pós-Graduação Criatividade e Inovação em Metodologias de Ensino Superior (PPGCIMES) - Universidade Federal do Pará (UFPA) - Belém - PA - Brasil

arllonlima@yahoo.com.br, \{mdiniz, mariane\} @ufpa.br

\begin{abstract}
The article presents the 7Cs Methodology, which consists of a proposal culminating in the product of the master of the stricto sensu postgraduate program in creativity and innovation in methodology of higher education of the Federal University of Pará. This methodology aims to minimize the difficulties faced by undergraduate students in Computer undergraduate courses or equivalent in the process of learning by providing the understanding of the algorithms basic contents based on a new form of pratice construction of algorithms, supported by Ausubel's Meaningful Learning theory (2000).
\end{abstract}

Resumo. $O$ artigo apresenta a Metodologia 7 Cs que consiste em uma proposta concebida como produto de mestrado do Programa de Pós-graduação stricto sensu em Criatividade e Inovação em Metodologias de Ensino Superior (PPGCIMES) da Universidade Federal do Pará (UFPA). Essa metodologia objetiva minimizar as dificuldades enfrentadas pelos discentes de graduação em cursos da área de Computação ou equivalentes no processo de aprendizagem e na compreensão dos conteúdos básicos da disciplina Algoritmos por meio de uma nova forma de praticar a construção de algoritmos, respaldada na teoria de Aprendizagem Significativa de Ausubel (2000).

\section{Introdução}

Muitos alunos chegam à universidade com deficiências em sua formação básica relacionadas à escrita, à interpretação textual, aos conceitos matemáticos, ao raciocínio lógico, à capacidade de abstração e à solução de problemas, habilidades consideradas importantes para a disciplina de algoritmos, normalmente ofertada no primeiro ano de formação. Tais deficiências são apontadas como fatores impactantes relacionados ao cancelamento ou abandono na disciplina de algoritmos, pelas dificuldades dos alunos na compreensão e abstração do conhecimento. Giraffa e Moreira (2013) enfatizam que a evasão em disciplinas dos níveis iniciais dos cursos de Computação não se trata de um tema novo, mas algo que muito vem sendo estudado, tanto em nível nacional quanto internacional.

Em cursos da área da computação, a disciplina de algoritmos é considerada como um grande desafio aos alunos. Muitas das expectativas dos alunos sobre a disciplina e o próprio curso de graduação são estremecidas ao se depararem com o novo conhecimento, o qual não fez parte da sua formação inicial e que exige conhecimentos específicos e integrados. Dessa maneira, para aqueles que possuem lacunas na 
formação, atender essas demandas é um grande desafio. Assim, muitos alunos ficam desmotivados e não se sentem capazes de desenvolver algoritmos com eficiência. Segundo Branco e Schuvartz (2007, p. 521):

Os cursos da área de computação e informática enfrentam um grande problema com as disciplinas de introdução à programação de computadores, as quais visam ensinar como utilizar o computador para solucionar problemas. Acadêmicos iniciantes, ao se depararem com a disciplina, sentemse incapazes de programar, devido ao conjunto de habilidade que programação exige como capacidade para solucionar problemas, raciocínio lógico, habilidade matemática, capacidade de abstração, entre outras.

Petry (2005), por exemplo, relata que as dificuldades inerentes aos alunos quando não solucionadas em tempo hábil, trarão muitos prejuízos em sua formação acadêmica e para os docentes, que precisam cumprir o que é exigido no currículo. Esse fator ocasiona problemas futuros nas exigências de competências e habilidades necessárias em outras disciplinas durante o curso. A autora aponta que uma das dificuldades principais na disciplina de algoritmos em cursos da Computação é a compreensão dos conteúdos básicos e a aplicação da lógica de programação na construção de algoritmos para resolução de problemas. Podemos dizer que esse aspecto está diretamente relacionado à encadeação de ideias e pensamentos para construção e solução de um problema por computador.

Outra implicação nas dificuldades apresentadas pelos discentes na disciplina está relacionada à forma tradicional de ensino, que minimamente leva em consideração a individualidade e ritmo de aprendizagem. Pouco se trabalha na perspectiva de desenvolver habilidades e competências, tais como: a compreensão, a autonomia, a interpretação e a resolução de problemas. Esse contexto pode ser alterado com a inserção de métodos adequados para construção do conhecimento dos alunos, por meio de metodologias que proporcionem e facilitem a compreensão dos conteúdos da disciplina.

\begin{abstract}
O ensino de Algoritmos na maioria das Instituições se dá através de aulas convencionais e essas não privilegiam o que se faz necessário para a aprendizagem desse conteúdo. São necessárias ações pedagógicas que contemplem esse processo, ou seja, são necessárias ações pedagógicas voltadas à aprendizagem para a Resolução de Problemas que permitem desenvolver capacidades como atenção, concentração, pensamento criativo e outras habilidades perceptuais psicomotoras indispensáveis para agilizar o raciocínio [RAPKIEWICZ et al., 2006, p. 04].
\end{abstract}

Levamos em consideração que, diferentemente de alguns conteúdos, como os relacionados à Biologia, à Matemática e ao Português, a disciplina de algoritmos aborda um conhecimento difícil de se fazer presente na grade curricular do ensino básico, principalmente em escolas públicas. Dessa forma, muitos alunos que saem diretamente do ensino médio e ingressam nos cursos de computação, nunca ouviram falar sobre o que é, e do que se trata a construção de um algoritmo, dificultando seu desempenho na disciplina. Os alunos percebem a disciplina e o conteúdo visto como algo distante da sua realidade e de difícil compreensão.

Um fato observado é que a maior parte dos alunos são egressos do ensino médio regular, que não tiveram base técnica de lógica ou algoritmos, o que contribui de forma direta para o aumento da dificuldade de aprendizado. Os alunos oriundos do segundo grau que fizeram o curso Técnico em Informática sempre apresentam maior facilidade nos conteúdos, o que 
direciona os índices de aprovação [VIEIRA; LIMA JUNIOR, VIEIRA, 2015, p. 13].

Neste contexto, é importante que o professor busque estratégias e metodologias de ensino que possam auxiliá-lo e contribuir com a aprendizagem dos estudantes, em busca de facilitar a compreensão sobre os conteúdos de algoritmos. De acordo com Berssanette (2016), uma das dificuldades de ensino da disciplina está justamente relacionada à ausência de metodologias adequadas, pois geralmente é ministrada de maneira tradicional, apenas com a teorização.

\section{Trabalhos Relacionados}

$\mathrm{Na}$ busca de referências que pudessem embasar teoricamente uma nova estratégia de ensino na disciplina de algoritmos, encontramos o autor Campos (2010) que, ao ministrar a disciplina de lógica de programação, verificou que mais de $60 \%$ dos alunos haviam sido reprovados. Esse resultado o fez refletir se o problema estava somente relacionado a sua forma de ensino. Ao realizar um levantamento percebeu que muitas IES passam pelo mesmo dilema, o estimulando a repensar sua maneira de ensinar e buscar uma nova estratégia para ministrar a disciplina. Surgiu, então, a metodologia ERMC $^{2}$ (Entender, Revisar, Melhorar, Complementar e Construir) que visa contribuir com o processo de ensino-aprendizagem na disciplina de Lógica de Programação ou similar, buscando desenvolver capacidades para leitura de algoritmos prontos, identificar erros, propor modificações, inserir novas ações e por fim ter a capacidade para construção de algoritmos.

Como reafirmado neste trabalho, aprender algoritmos não é tarefa fácil para muitos, por isso a necessidade em incentivar e encorajar o uso de metodologias que dinamizem o ensino e a inclusão dos alunos na construção dos saberes. Sousa (2011) em sua dissertação de mestrado propôs a aplicação da metodologia ativa Aprendizagem Baseada em Problemas (PBL) para o ensino de conteúdos computacionais e algoritmos e técnicas de programação, no qual acredita que a estratégia metodológica da PBL rompe com os paradigmas do ensino tradicional e centraliza o conhecimento no aluno, valorizando o contexto e os seus conhecimentos prévios, potencializando o ensino e aprendizagem de computação em um curso de licenciatura.

Os autores Giraffa et al. (2015) apresentaram os resultados e as lições aprendidas relacionadas ao uso de uma metodologia para apoiar o ensino de programação para iniciantes. Buscaram criar alternativas para ampliar o espaço de encontros presenciais com a criação de uma sala de aula virtual e uso de enunciados de exercícios que nos permitissem aproximar dos interesses dos alunos por meio de situações ancoradas nos seus hábitos de lazer. Tinham como objetivo apresentar a questão dos desafios e possibilidades da integração de múltiplos espaços e ferramentas existentes na Internet, a questão da motivação para realizar as tarefas a partir da oferta de exercícios que estejam relacionados ao cotidiano dos alunos.

Os trabalhos evidenciam aspectos comuns e o objetivo de tornar a aprendizagem mais atrativa para o processo de aprendizagem na disciplina de algoritmos. Este artigo apresenta uma proposta de uma nova metodologia que corrobora para facilitar a compressão e solução de problemas de computador por meio de uma nova forma de exercitar a construção de algoritmos, potencializando o processo de aprendizagem dos alunos sobre os conteúdos ministrados. 


\section{Teoria de Aprendizagem Significativa}

O ensino superior exige um vasto conhecimento e dedicação do docente que nele está inserido, igualmente ao qualquer outro formador, este profissional necessita de saberes que possam auxiliá-lo nesta jornada do ensinar, para que, dessa maneira, alcance meios de tornar a sala de aula eficiente e a aprendizagem para o aluno mais efetiva, evitando um sistema somente conteudista, para fomentar uma aprendizagem significativa.

Ausubel (2000) elaborou sua Teoria da Aprendizagem Significativa ao verificar que abordagem tradicional era pouco producente e que os conceitos adquiridos, na verdade, não eram interativos, por isso, não eram construídos e internalizados pelos alunos. Assim, a teoria proposta por ele, envolve uma análise das formas de ensinar e de aprender, examinando os contextos reais de sala da aula.

Conforme Ausubel (2000), a aprendizagem, para ser significativa, deve envolver os mecanismos, que possibilitem a mudança na maneira com que o aluno aprende, assim:

O conhecimento é significativo por definição. É o produto significativo de um processo psicológico cognitivo ("saber") que envolve a interação entre ideias "logicamente" (culturalmente) significativas, ideias anteriores ("ancoradas") relevantes da estrutura cognitiva particular do aprendiz (ou estrutura dos conhecimentos deste) e o "mecanismo" mental do mesmo para aprender de forma significativa ou para adquirir e reter conhecimentos [AUSUBEL, 2000, p. 04].

Ao propor a aprendizagem significativa, Ausubel (2000), partiu do princípio de que os indivíduos só aprendem quando utilizam conteúdos existentes em sua estrutura cognitiva, chamados por ele de subsunçores, que servem como âncoras para interação entre os novos e conhecimentos anteriores. Para Moreira (2011, p.18) "subsunçor é, portanto, um conhecimento estabelecido na estrutura cognitiva do sujeito que aprende e que permite, por interação, dar significado a outros conhecimentos".

Para Ausubel (2000), existem três formas de relações na Aprendizagem Significativa, a subordinada (de subsunção), a subordinante e a combinatória. A subordinada é considerada a mais comum e simples na qual o novo conhecimento se "ancora" ao conhecimento preexistente adquirindo significado. A subordinante é aquela que promove a reorganização cognitiva conforme os conhecimentos relacionados e aprendidos por subsunção. Já a combinatória, trata da necessidade de um conjunto de conhecimentos prévios para que se construa um novo conhecimento, realizando a combinação entre as formas subordinada e subordinante.

As formas de aprendizagem significativa, citadas acima, podem ser utilizadas como complementares, como uma sequência de ações que podem ser construídas para o processo de aprendizagem. Diante ao exposto concebemos e desenvolvemos a Metodologia 7Cs (Compreender, Conceber, Completar, Compatibilizar, Corrigir, Construir e Contribuir) fundamentada em princípios da teoria Aprendizagem Significativa de Ausubel (2000), levando em consideração em sua estrutura a conexão entre os conhecimentos adquiridos pelos alunos durante a disciplina de algoritmos.

\section{A importância da prática para a disciplina de algoritmos}

O processo para construção do conhecimento do aluno na aprendizagem de algoritmo é algo novo a sua estrutura cognitiva, o que representa muitas vezes um bloqueio ou 
resistência ao aprendizado dos conteúdos básicos da disciplina. De acordo com Falckembach e Araujo (2006, p. 01), "resolver problemas inclui uma predisposição para o questionamento de quais os processos cognitivos que devem ser utilizados, a fim de gerar o conhecimento necessário à resolução do problema. Envolve as operações de pensar, de análise, de síntese e de avaliação". Nesse sentido, tal resistência na aprendizagem e bloqueio na utilização de processos cognitivos importantes para construção do conhecimento, impede que os alunos consigam um bom desempenho na disciplina de algoritmos.

A disciplina de algoritmos é feita principalmente da prática de resolução de problemas por computador em que se torna um processo muito importante para que os alunos desenvolvam habilidades e competências necessárias a construção de algoritmos com eficiência. Timmermann (2015, p. 104), ressalta que "exercitar, normalmente, demanda mera aplicação de técnicas" o que para ela é insuficiente para aprendizagem de algoritmos, pois pouco desenvolve funcionalidades inéditas nos exercícios propostos para os alunos das duas turmas observadas.

$\mathrm{O}$ ato de praticar na disciplina de algoritmos é crucial para concretizar os conhecimentos adquiridos durante o processo de aprendizagem, mas é importante ter o cuidado para que a prática dos alunos não se resuma apenas na aplicação de técnicas, que inibem seu processo criativo para solucionar problemas. Devemos estimular a construção significativa do seu aprendizado sobre os conteúdos.

Aprender a desenvolver algoritmos é uma tarefa complexa, com inúmeras barreiras para sua compreensão. Assim, é necessário propor soluções que ajudem ao professor e ao aluno a transporem os obstáculos que impedem a compreensão do conteúdo a ser ministrado. Nesse sentido propomos a Metodologia 7Cs.

\section{Publico}

A Metodologia 7Cs possui como publico, professores e alunos de cursos de graduação que contemplam a disciplina Algoritmos e equivalentes.

\section{Descrição da Metodologia 7Cs}

A partir da premissa de que a maioria dos alunos possuem pouca ou nenhuma experiência com a construção de algoritmos [Campos 2011] e que possuem deficiências em habilidades e competências, como a interpretação textual, a capacidade de abstração, a solução de problemas, conceitos matemáticos, entre outras [Berssanette 2016], exigidas pela disciplina, acreditamos que dificilmente os alunos conseguirão aprender a construir algoritmos sem dificuldades e com eficiência, se não conseguirem transpor as dificuldades existentes. Portanto, a metodologia proposta pretende facilitar a compreensão dos conteúdos básicos da disciplina de algoritmos, buscando desenvolver habilidades e competências, a partir do desenvolvimento de uma sequência lógica de aprendizagem.

A Metodologia 7Cs contém em sua estrutura sete dimensões (Compreender, Conceber, Completar, Compatibilizar, Corrigir, Construir e Contribuir), cada uma delas possui um único objetivo, que traça um caminho para construção do conhecimento sobre os conteúdos trabalhados na disciplina. O Quadro 1 apresenta a descrição de cada uma das dimensões com objetivos, habilidades e competências a serem desenvolvidas e pré-requisito. 


\begin{tabular}{|c|c|c|c|c|}
\hline DIMENSÃO & DESCRIÇÃO & OBJETIVOS & $\begin{array}{l}\text { HABILIDADES E } \\
\text { COMPETÊNCIAS }\end{array}$ & PRÉ-REQUISITOS \\
\hline Compreender & $\begin{array}{l}\text {-Na dimensão Compreender, os alunos } \\
\text { devem entender o novo conhecimento, } \\
\text { por meio da interpretação e análise de } \\
\text { algoritmos simples. }\end{array}$ & $\begin{array}{l}\text {-Estimular nos alunos a capacidade de } \\
\text { interpretação de trechos ou de algoritmos } \\
\text { inteiros e simples, já construídos. }\end{array}$ & $\begin{array}{l}\text { - Compreender e interpretar os } \\
\text { funcionamentos da estrutura de um } \\
\text { algoritmo. }\end{array}$ & $\begin{array}{l}\text { - Conhecer os conceitos básicos da } \\
\text { estrutura e a linguagem de } \\
\text { programação a ser trabalhada. }\end{array}$ \\
\hline Conceber & $\begin{array}{l}\text {-Na dimensão Conceber, o aluno, após } \\
\text { passar pelo processo de compreensão, } \\
\text { será levado a produzir seus primeiros } \\
\text { algoritmos a partir de situações } \\
\text { problemas. }\end{array}$ & $\begin{array}{l}\text {-Estimular a capacidade de solução de } \\
\text { problemas, ao conceber seus primeiros } \\
\text { algoritmos. }\end{array}$ & $\begin{array}{l}\text { Interpretar os comandos das } \\
\text { questões; } \\
\text { Desenvolver a capacidade de } \\
\text { solução de problemas. }\end{array}$ & $\begin{array}{l}\text {-Passar pela dimensão } \\
\text { Compreender, para obter } \\
\text { conhecimentos específicos na } \\
\text { construção de um algoritmo. } \\
\text { - Conhecer minimamente a } \\
\text { linguagem de programação a ser } \\
\text { utilizada pelo professor. }\end{array}$ \\
\hline Completar & $\begin{array}{l}\text {-Na dimensão Completar, partindo do } \\
\text { princípio de que compreenderam o } \\
\text { conteúdo e foram capazes de conceber } \\
\text { seus primeiros algoritmos, serão } \\
\text { capazes de analisar um algoritmo } \\
\text { incompleto e perceber o está faltando } \\
\text { para ser executado. }\end{array}$ & $\begin{array}{l}\text {-Estimular a capacidade de analisar um } \\
\text { algoritmo já construído, para identificar } \\
\text { os elementos que faltam para se tornar } \\
\text { corrente e executável. }\end{array}$ & $\begin{array}{l}\text { - Desenvolver a capacidade de } \\
\text { percepção de erros. } \\
\text {-Interpretar os comandos das questões } \\
\text { e códigos. } \\
\text {-Desenvolver a capacidade de ajuste } \\
\text { algoritmo. }\end{array}$ & $\begin{array}{l}\text {-Passar pelas dimensões } \\
\text { Compreender e Conceber, que } \\
\text { desenvolveram conhecimentos } \\
\text { iniciais de construção de } \\
\text { algoritmos. } \\
\text { - Saber os elementos necessários } \\
\text { para execução de um algoritmo. }\end{array}$ \\
\hline Compatibilizar & $\begin{array}{l}\text {-Na dimensão Compatibilizar, os } \\
\text { alunos devem, a partir de um } \\
\text { algoritmo já construído, porém } \\
\text { apresentado de forma desordenada, } \\
\text { identificar quais comandos devem ser } \\
\text { realocados para que possa ser } \\
\text { executável. }\end{array}$ & $\begin{array}{l}\text {-Estimular a capacidade de organização e } \\
\text { encadeamento das informações de } \\
\text { maneira ordenada na construção de um } \\
\text { algoritmo. }\end{array}$ & $\begin{array}{l}\text { Desenvolver a capacidade de } \\
\text { organizar o encadeamento das ideias. } \\
\text {-Interpretar os comandos das } \\
\text { questões; } \\
\text {-Desenvolver a capacidade de ajuste } \\
\text { de algoritmo. }\end{array}$ & $\begin{array}{l}\text {-Passar pelas dimensões } \\
\text { Compreender, Conceber e } \\
\text { Completar, que possibilitarão a } \\
\text { capacidade de o aluno reordenar } \\
\text { um algoritmo. } \\
\text { - Saber os elementos necessários } \\
\text { para execução de um algoritmo. }\end{array}$ \\
\hline
\end{tabular}

Quadro 1: Descrição da Metodologias 7Cs (Continua...) 


\begin{tabular}{|c|c|c|c|c|}
\hline DIMENSÃO & DESCRIÇÃO & OBJETIVOS & $\begin{array}{l}\text { HABILIDADES E } \\
\text { COMPETÊNCIAS }\end{array}$ & PRÉ-REQUISITOS \\
\hline Corrigir & $\begin{array}{l}\text { - Na dimensão Corrigir, os alunos } \\
\text { receberam um código com erro, o qual } \\
\text { deve ser analisado e corrigido. }\end{array}$ & $\begin{array}{l}\text {-Estimular a capacidade de analisar e } \\
\text { perceber erros em algoritmos já } \\
\text { construídos. }\end{array}$ & $\begin{array}{l}\text { - Desenvolver a capacidade de análise } \\
\text { de algoritmos. } \\
\text {-Corrigir códigos com erros. } \\
\text {-Desenvolver a capacidade de ajuste } \\
\text { de algoritmo. }\end{array}$ & $\begin{array}{l}\text {-Passar pelas dimensões } \\
\text { Compreender, Conceber, } \\
\text { Completar e Compatibilizar, que } \\
\text { irão capacitar os alunos a uma } \\
\text { maior sensibilidade ao analisar um } \\
\text { código de algoritmo. } \\
\text { - Saber os elementos necessários } \\
\text { para execução de um algoritmo. }\end{array}$ \\
\hline Construir & $\begin{array}{l}\text {-Na dimensão Construir, os alunos } \\
\text { devem utilizar todos os } \\
\text { conhecimentos já adquiridos, para } \\
\text { construir a solução de problemas mais } \\
\text { complexos. }\end{array}$ & $\begin{array}{l}\text {-Estimular a solução de problemas que } \\
\text { necessita da construção de algoritmos } \\
\text { com nível de exigência maior. }\end{array}$ & $\begin{array}{l}\text {-Interpretar os comandos das } \\
\text { questões. } \\
\text { - Desenvolver a capacidade de } \\
\text { solução de problemas. } \\
\text {-Construir algoritmos com eficiência. } \\
\end{array}$ & $\begin{array}{l}\text {-Passar pelas dimensões } \\
\text { Compreender, Conceber, } \\
\text { Completar e Compatibilizar e } \\
\text { Corrigir, que desenvolveram } \\
\text { habilidades e competências } \\
\text { importantes para os alunos } \\
\text { desenvolvam algoritmos com } \\
\text { eficiência. } \\
\text { - Saber interpretar os comandos, } \\
\text { analisar, organizar, corrigir e } \\
\text { solucionar. }\end{array}$ \\
\hline Contribuir & $\begin{array}{l}\text {-Na dimensão Contribuir os alunos } \\
\text { deverão resolver um problema de } \\
\text { maneira colaborativa. }\end{array}$ & $\begin{array}{l}\text {-Estimular a solução de problemas de } \\
\text { maneira colaborativa, para troca de } \\
\text { informações de maneira significativa. }\end{array}$ & $\begin{array}{l}\text {-Desenvolver a capacidade de } \\
\text { trabalhar em grupo. } \\
\text { - Desenvolver a capacidade } \\
\text { colaborativa. } \\
\text {-Potencializar a solução de problemas. } \\
\text { Aperfeiçoar algoritmos. }\end{array}$ & $\begin{array}{l}\text {-Passar pelas dimensões } \\
\text { Compreender, Conceber, } \\
\text { Completar e Compatibilizar e } \\
\text { Corrigir e Construir, para } \\
\text { concretizar a construção do } \\
\text { conhecimento de maneira } \\
\text { colaborativa. }\end{array}$ \\
\hline
\end{tabular}

Quadro 1: Descrição da Metodologias 7Cs (Concluída) 
As sete dimensões da Metodologia 7Cs foram divididas em três fases inspiradas nas três categorias de aprendizagem significativa (Subordinada, Superordenada e Combinatória) de Ausubel (2000). As fases são: Descoberta, Aperfeiçoamento e Consolidação (Ver Quadro 2).

\begin{tabular}{|l|l|l|l|}
\hline \multicolumn{1}{|c|}{ FASE } & \multicolumn{1}{|c|}{ CARACTERÍSTICAS } & DIMENSÕES & $\begin{array}{l}\text { CATEGORIA DE } \\
\text { APRENDIZAGEM } \\
\text { SIGNIFICATIVA }\end{array}$ \\
\hline Descoberta & $\begin{array}{l}\text { Fase em que o aluno inicia o contato } \\
\text { com os conceitos e estruturas básicas } \\
\text { de algoritmos. }\end{array}$ & $\begin{array}{l}\text { Compreender } \\
\text { Conceber }\end{array}$ & Subordinada \\
\hline Aperfeiçoamento & $\begin{array}{l}\text { Fase em que os alunos aprendem } \\
\text { alguns aspectos importantes a serem } \\
\text { considerados na construção de } \\
\text { algoritmos como: saber da importância } \\
\text { de ter todos os elementos no código, } \\
\text { organização dos comandos e de } \\
\text { identificar e corrigir erros. }\end{array}$ & $\begin{array}{l}\text { Compatibilizar } \\
\text { Corrigir }\end{array}$ & Superordenada \\
\hline Consolidação & $\begin{array}{l}\text { Fase em que os alunos devem aplicar } \\
\text { todos os conhecimentos adquiridos } \\
\text { anteriormente de maneira individual e } \\
\text { colaborativa. }\end{array}$ & $\begin{array}{l}\text { Construir } \\
\text { Contribuir }\end{array}$ & Combinatória \\
\hline
\end{tabular}

\section{Quadro 2: Fases da Metodologia 7Cs}

A primeira fase Descoberta é constituída por duas dimensões: Compreender e Conceber. Essa fase inicia com a primeira dimensão Compreender, na qual os alunos irão realizar a interpretação de algoritmos, em busca de estimular a capacidade de ler e entender as funcionalidades da estrutura trabalhada (por exemplo na Estrutura de Seleção) presentes nos trechos e/ou algoritmos simples completos, mesmo que não tenha sido feito por ele. A primeira dimensão é muito importante para próxima, Conceber, pois é a partir da compreensão da estrutura de algoritmos ministrada pelo professor, que os alunos devem conceber seus primeiros algoritmos.

$\mathrm{Na}$ segunda fase, Aperfeiçoamento, os alunos devem aplicar os conhecimentos adquiridos na primeira fase. Esta fase (Aperfeiçoamento) compreende: a dimensão Completar, que tem objetivo de verificar a partir de um algoritmo já construído, elementos que precisam ser inseridos; já a dimensão Compatibilizar, consiste em organizar um algoritmo concebido de forma desorganizada, para que se torne executável; e a dimensão Corrigir, consiste na correção de algoritmos já construídos, que apresentam erros.

A terceira e última fase é Consolidação, na qual os alunos precisam unir todas as habilidades e competências em um único objetivo, a solução de problemas, para construir algoritmos com eficiência e validade. Esta fase compreende: a dimensão Construir, na qual os alunos realizarão algoritmos com um nível de exigência maior; e a dimensão Contribuir, que se configura na construção colaborativa de algoritmos.

Ausubel (2000) afirma que a aprendizagem significativa ocorre mediante a ancoragem entre as ideias e conhecimentos anteriores relevantes, presentes na estrutura 
cognitiva dos indivíduos, como forma de adquirir e reter novos conhecimentos. Nesse sentido, pensamos na divisão em três fases, na qual ocorre a solidificação de conhecimentos específicos que consideramos importantes para construção e elaboração de algoritmos, para que pudéssemos elencar elementos por meio da ancoragem de conhecimentos adquiridos de uma fase para outra, como ilustrado na Figura 1 a seguir.

\section{ANCORAGEM DE CONHECIMENTO}

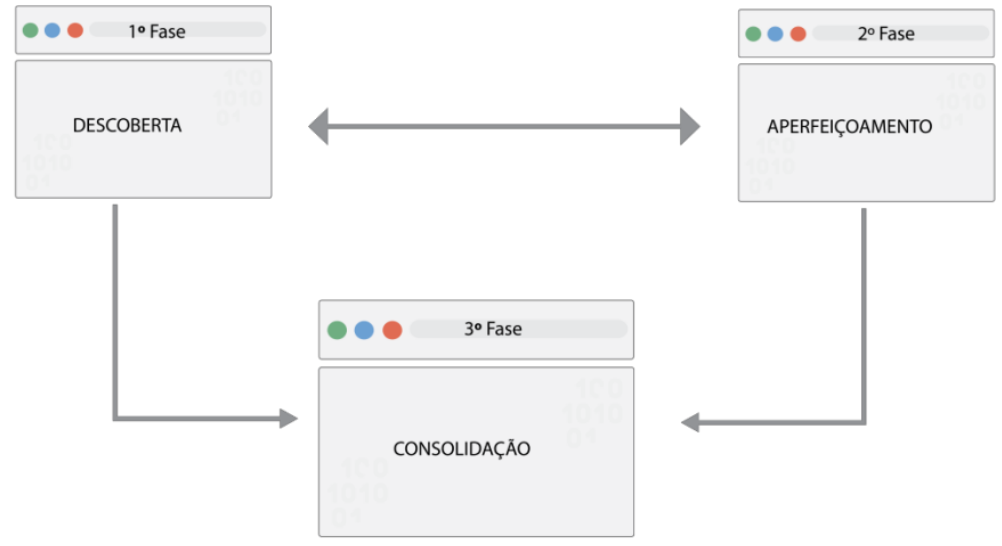

Figura 1: fases da Metologia 7Cs

A primeira fase (Descoberta) serve de âncora para a segunda (Aperfeiçoamento) e as duas (tanto a primeira quanto a segunda) para a terceira (Consolidação). A ancoragem de conhecimentos entre as fases é um ponto importante para o desenvolvimento da aprendizagem significativa dos alunos. Além disso, a forma de distribuição da Metodologia 7Cs corrobora para sua aplicação na disciplina Algoritmos ao considerar a quantidade de aulas para cada estrutura de algoritmos. Propomos a seguir alguns exemplos de aplicação da metodologia em forma de aulas.

\section{Relato de experiência e impressões sobre a aplicação da Metodologia 7Cs}

Para o teste piloto da Metodologia 7Cs, foi aplicada no Programa de Nivelamento em Algoritmos (PNA) no Instituto de Ciências Exatas e Naturais (ICEN) da Universidade Federal do Pará (UFPA), para calouros do curso de graduação em Ciência da Computação. O PNA consiste em uma iniciativa de discentes, que objetiva introduzir, por meio de um curso de nivelamento, os conteúdos básicos de algoritmos como forma de auxílio ao processo de aprendizagem na disciplina Algoritmos. A linguagem de programação utilizada na experiência foi Python. O curso aconteceu em quatro aulas diárias durante quatro dias, com a participação de vinte e três calouros.

O desenvolvimento do curso de nivelamento ocorreu mediante a participação de monitores, que são discentes de graduação em Ciência da Computação, responsáveis por ministrar as aulas. Dessa forma, realizamos a instrução dos monitores para aplicação da Metodologia 7Cs em que apresentamos a sua descrição, seus objetivos e algumas possibilidades de trabalhar as atividades em sala, para que pudessem utiliza-la.

\subsection{Aplicação da Metodologia 7Cs}

$\mathrm{Na}$ aplicação da Metodologia 7Cs os monitores ficaram livres para encontrar a melhor forma de conduzir o conteúdo a ser ministrado durante as aulas com o uso da 
metodologia. A ideia era perceber se os monitores conseguiriam aplicar a metodologia sem nossa interferência, para que pudessem utiliza-la a partir das suas próprias impressões e compreensão da proposta que desenvolvemos.

No primeiro dia de curso os monitores iniciaram com a aplicação do jogo intitulado M7C (Metodologia 7Cs), desenvolvido em uma das disciplinas do mestrado. O jogo foi criado, por julgarmos ser importante a familiarização dos discentes com a Metodologia 7Cs, antes da sua aplicação, visto que iria conduzir a forma de praticar o conteúdo a ser ministrado durante o curso. Buscamos tornar a interação com a Metodologia 7Cs mais prazerosa e por isso decidimos desenvolver o jogo com o propósito de apresentar ludicamente aos alunos participantes do curso.

O jogo é estruturado em forma de cartas com situações problemas e desafios (ver Figura 2) e contém seis territórios. Cada território representa uma dimensão da Metodologia 7Cs, são elas Compreender, Conceber, Completar, Compatibilizar, Corrigir e Construir. A dimensão Contribuir está presente em todo o jogo por as atividades serem realizadas de forma colaborativa, não constituindo, portanto, um dos territórios. Dessa maneira, a turma foi dividida em grupos para resolver as situações problemas. A seguir na Figura 2 são apresentadas as Cartas Desafio do jogo.

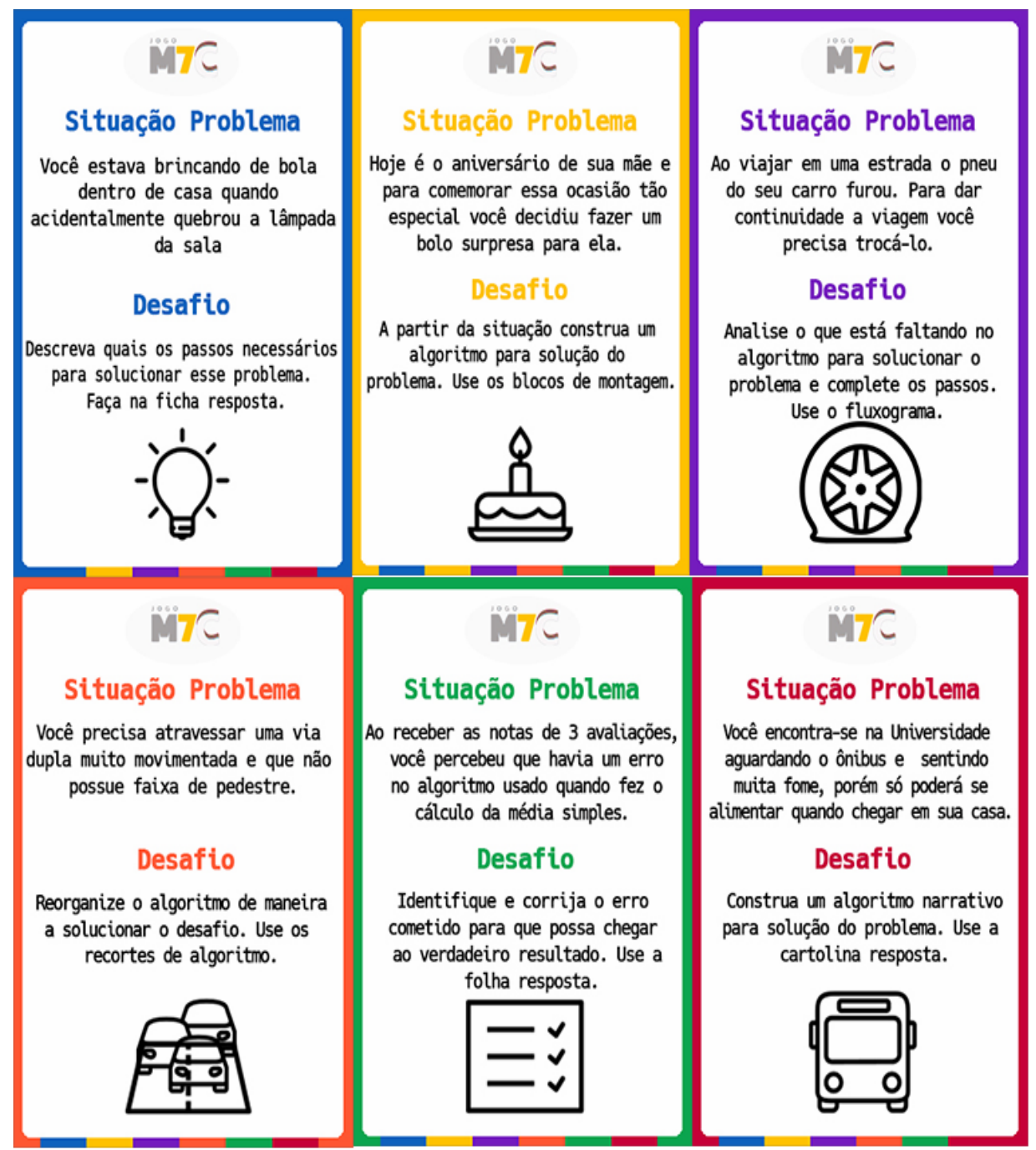

Figura 2: Cartas Desafio do jogo M7C 
Além de apresentar a Metodologia 7Cs, o jogo também trabalhou conceitos iniciais de algoritmos como: sobre o que é um algoritmo, a estrutura sequencial, formas de representação, estrutura de condição e algoritmo narrativo. Durante o jogo os monitores eram responsáveis por conduzir todo o processo a cada desafio realizado e ao analisar e verificar as soluções dadas pelos alunos validavam a resposta do grupo vencedor, em cada uma das dimensões. A seguir a Figura 3 mostra os monitores realizando a avaliação das respostas dos alunos.
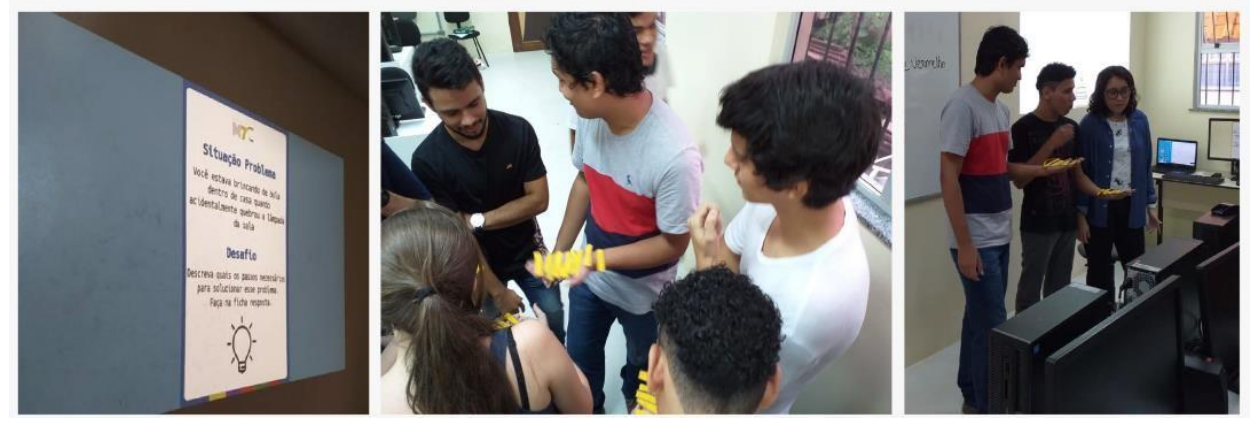

Figura 3: Aplicação do jogo M7C

Após cada desafio os monitores realizaram o feedback para os alunos sobre a dimensão correspondente à Metodologia 7Cs e sobre os conteúdos iniciais trabalhados. No segundo dia primeiramente os alunos participantes do curso passaram por um processo de ambientação da linguagem de programação Python com pequenos exemplos para que o conteúdo pudesse ser ministrado (Estrutura de Seleção). Logo após passaram para aplicação de duas dimensões da Metodologia 7Cs a de Compreender e Conceber que consiste na primeira fase, Descoberta.

Para a dimensão Compreender os monitores exibiam em slide trechos de códigos de algoritmos, para que os alunos pudessem expressar o que estavam entendendo do código. Incialmente utilizaram caneta e papel para descrever suas impressões e posteriormente realizaram um relato aberto sobre o que haviam interpretado após analisar o código apresentado. Nesse momento houve uma grande interação e compartilhamento de pensamentos diversificados que tornaram a aula muito interessante. Já a dimensão Conceber ocorreu mediante a construção dos primeiros algoritmos com auxilio dos monitores (ver Figura 4), relacionados a soma, subtração, divisão e a média, que constituiu a conexão inicial e descoberta dos alunos com a prática.

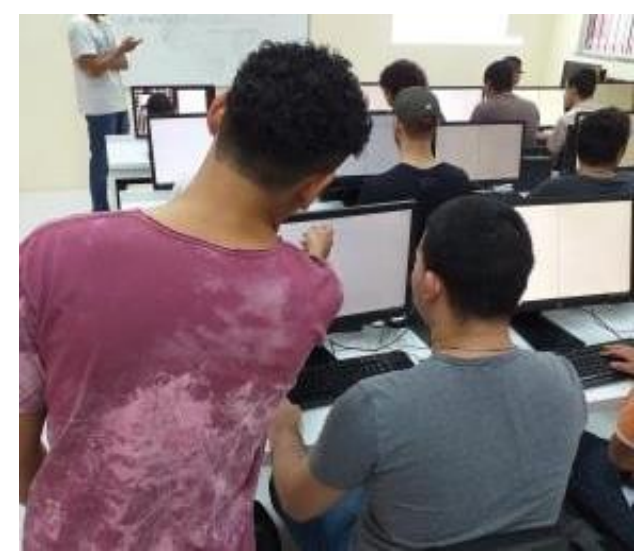

Figura 4: Construção dos primeiros algoritmos dos alunos no curso 
No terceiro dia resolvemos aplicar a Metodologia 7Cs de uma maneira diferente. Colocamos aos monitores o desafio de utilizarem o Kahoot!, que consiste em uma plataforma de aprendizagem baseada em jogos, para aplicação da segunda fase Aperfeiçoamento. Os monitores criaram para cada dimensão (Completar, Compatibilizar e Corrigir) da segunda fase, 10 questões que os alunos deveriam responder em um tempo determinado. No Kahoot! existem três formas possíveis de desenvolver atividades são elas: modo Questionário com perguntas e respostas, modo Desordem para montar a ordem correta da informação presente e modo Pesquisa em que podemos realizar levantamentos importantes sobre as impressões dos alunos sobre objetos de pesquisa. As questões apareciam projetadas e nos computados dos alunos apareciam as cores que correspondiam as respostas e marcavam a cor da alternativa que consideravam correta (ver Figura 5).

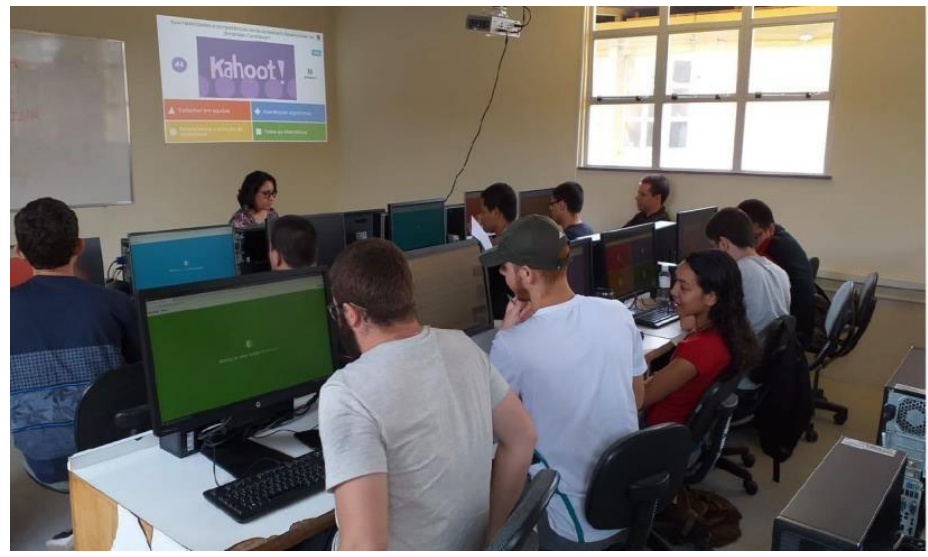

Figura 5: Aplicação da Metodologia 7Cs no Kahoot

As questões de Completar foram feitas no modo Questionário em que eram mostrados trechos de códigos de algoritmos faltando determinados elementos e os alunos deveriam identificar entre as alternativas qual era a correta e o elemento necessário para que tornasse o algoritmo executável. A dimensão Compatibilizar foi realizada no modo Desordem em que deveriam saber a ordem de trechos de códigos de algoritmos e organizar de maneira correta, para torna-lo executável. E a dimensão Corrigir também foi realizada no modo Questionário para verificar em trechos de códigos de algoritmos qual era o erro e escolher a alternativa que pudesse corrigir e solucionar o problema. O uso da ferramenta (Kahoot) nos mostrou novas possibilidades de aplicação da Metodologia 7Cs por tornar a aula muito mais dinâmica e atrativa, não perdendo o seu valor como uma proposta de aprendizagem.

No mesmo dia passamos para a terceira fase Consolidação que compreende as dimensões Construir e Colaborar da Metodologia 7Cs. Para a dimensão Construir os monitores passaram questões com um maior nível de exigência de acordo com a proposta do curso de nivelar os conhecimentos dos conteúdos básicos de algoritmos. A aplicação das questões levou em consideração os conteúdos ministrados no curso. As questões foram disponibilizadas em sala e os alunos eram desafiados a construírem de maneira individual, ficando livres para solucionar os problemas no papel e depois no computador ou só no computador. Já para a dimensão Colaborar os monitores tiveram a ideia desenvolver uma atividade fora de sala (ver Figura 6) sobre a travessia de missionários e canibais para o outro lado do rio. 


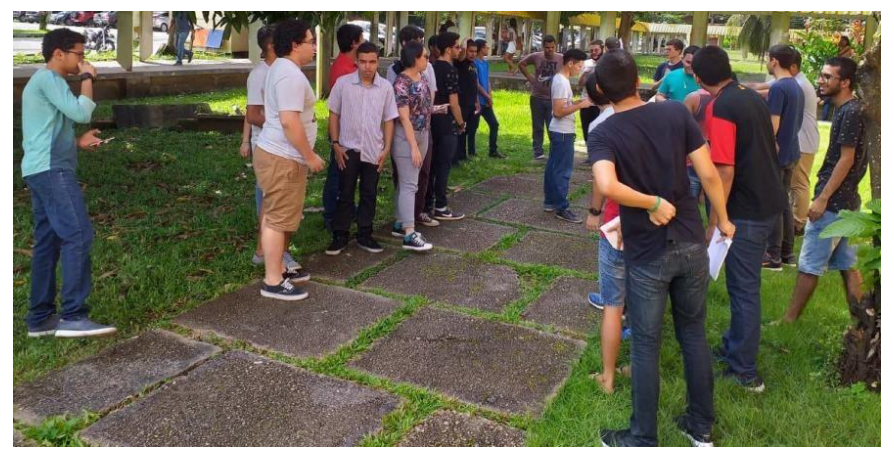

Figura 6: Aplicação da Metodologia 7Cs fora de sala de aula

Nessa atividade, primeiramente os alunos eram instruídos sobre a questão desafio e suas particularidades. Após a explicação passaram a escrever no papel a possível solução. O objetivo era que todos passassem para o outro lado sem que houvesse em nenhum momento um número maior de canibais em ambos os lados. Essa é uma questão clássica para exemplificar os passos para se chegar a uma solução de problemas e a conceituação de algoritmo pelas sequencias de passos realizados. É importante ressaltar que a Metodologia 7Cs estava sendo aplicada para alunos iniciantes recém chegados na universidade. Portanto, a atividade se torna complexa pela necessidade de se trabalhar em equipe e tentar chegar a um consenso para solução do problema.

Algumas equipes tiveram dificuldades em concatenar as ideias e acabaram tendo dificuldades no inicio da atividade, porém ao final todas conseguiram finalizar o algoritmo com sucesso. A colaboração entre os alunos possibilita a troca de conhecimentos e potencializa a compressão e o aprendizado dos conteúdos ministrados na disciplina de algoritmos, pois todos possuem conhecimentos particulares que ao compartilharem se integram.

Após a atividade para finalizar o curso realizamos ainda no Kahoot! uma pergunta para os alunos participantes com o propósito de ver a percepção deles sobre a potencialidade da Metodologia 7Cs para compreensão dos conteúdos ministrados. Dessa forma, realizamos o seguinte questionamento apresentado na Figura 7 a seguir.

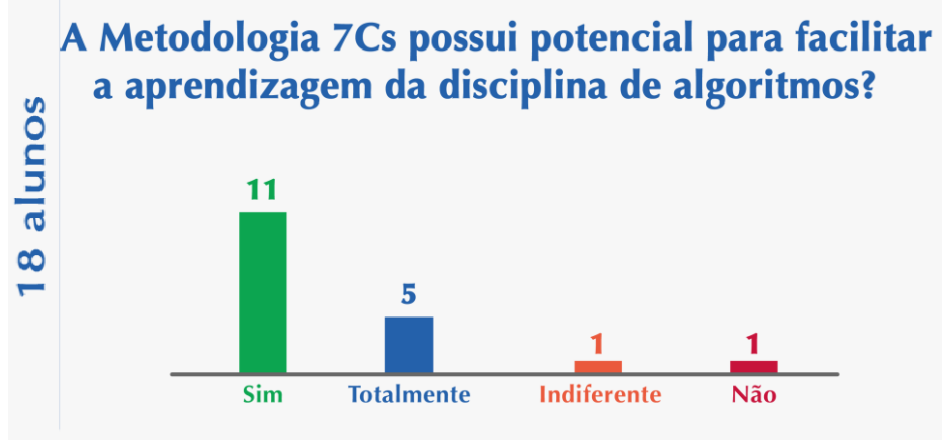

Figura 7: Resultado da percepção dos alunos sobre a Metodologia 7Cs

Da pesquisa realizada participaram dezoito alunos, dos quais onze disseram que "Sim", cinco "Totalmente", um "Indiferente" e um "Não". Dessa maneira acreditamos que a Metodologia 7Cs foi bem avaliada, visto que a maioria acredita que a metodologia desenvolvida possui sim potencial para contribuir com os mesmos durante seu processo 
de aprendizagem.

A aplicação da Metodologia 7Cs no PNA se tratou de um teste piloto que teve como objetivo verificar as possibilidades de trabalhar os conteúdos ministrados na disciplina de algoritmos e se outras pessoas, nesse caso os monitores, conseguiriam aplica-la a partir das instruções realizadas comtemplando o objetivo de cada dimensão presente na metodologia, sem a intervenção na forma de como seria conduzida.

\section{Considerações finais}

A disciplina de algoritmos nos cursos de computação é considerada uma das mais importantes, pois serve de base para as demais disciplinas dos cursos de graduação na área da computação e em áreas afins. Por esse motivo se torna essencial que os alunos possam ter a melhor base e aproveitamento na disciplina possível.

Durante a trajetória no Programa de Pós-Graduação em Criatividade e Inovação em Metodologias de Ensino Superior (PPGCIMES), muitas possibilidades e ideias surgiram. Durante observação participante na disciplina de algoritmos no primeiro e segundo semestre de 2018 percebemos as reais necessidades dos alunos e unimos ao que é mais importante nesse processo de construção de conhecimento, que é a parte prática da disciplina, surgindo assim a Metodologia 7Cs, que busca por meio da teoria da Aprendizagem Significativa criada por Ausubel (2000), minimizar as dificuldades dos alunos e facilitar a compreensão dos conteúdos por meio de uma sequência lógica de ações que sistematizam uma nova maneira de exercitar a construção de algoritmos.

Na aplicação da Metodologia 7Cs no Programa de Nivelamento em Algoritmos (PNA) percebemos que os monitores, não só compreenderam as instruções dadas inicialmente, como conseguiram aplicar a metodologia, de maneira coerente com a sua proposta. Além disso, assim como os monitores os alunos participantes do curso conseguiram facilmente assimilar as atividades e compreenderam a proposta de cada uma das dimensões. Esse fato se torna um indicio da viabilidade e aplicabilidade da Metodologia 7Cs para conduzir a parte prática da disciplina Algoritmos.

$\mathrm{O}$ artigo teve como objetivo apresentar uma metodologia intitulada Metodologia 7Cs criada como produto de dissertação de mestrado, em busca de minimizar as dificuldades encontradas por meio de uma nova maneira de praticar a construção de algoritmos. Presumimos que a Metodologia 7Cs possa subsidiar outros cursos superiores com o intuito contribuir com a formação e trajetória acadêmica dos discentes de curso de graduação, que contemplam a disciplina Algoritmos e equivalentes.

Como trabalhos futuro vamos aplicar a Metodologia 7Cs no primeiro semestre de 2019 em uma turma de graduação no curso de Bacharelado em Ciência da Computação e materializar a metodologia em forma de um material de orientações que auxilie outros professores em sua aplicação.

\section{Referências Bibliográficas}

Ausubel, D. P. (200). Aquisição e retenção de conhecimentos. Lisboa: Plátano Edições Técnicas. Tradução do original The acquisition and retention of knowledge.

Branco, N. W. C.; Schuvartz A. A.(2007). Ferramenta Computacional de Apoio ao Processo de Ensino-Aprendizagem dos Fundamentos de Programação de Computadores. In: Simpósio Brasileiro de Informática na Educação (SBIE), v. 28, 
São Paulo, SP. Anais... p. 520-528.

Berssanette, J. H. (2016). Ensino de programação de computadores: uma proposta de abordagem prática baseada em Ausubel. Ponta Grossa, PR: UTFP, 2016. Originalmente apresentada como dissertação de mestrado, Universidade Tecnológica Federal do Paraná. Ponta Grossa.

Campos, R. L. B. L. (2010). ERM2C: Uma metodologia para melhoria do ensinoaprendizado de lógica de programação. In: VIII Workshop de Educação e Informática, v.3, 2010, Maceió, AL. Anais... p. 1-3.

Campos, R. L. B. L. (2011). ERM2C Methodology: The new strategy to improve the learning/teaching process in algorithm. In: $8^{\circ}$ Congresso Internacional de Gestão de Tecnologia e Sistemas De Informação - Contecsi, v.8, 2011, São Paulo, SP. Anais..., p. 1-14.

Falckembach, G. A. M.; Araújo, F. V. (2006). Aprendizagem de Algoritmos: dificuldades na resolução de problemas. Universidade Luterana do Brasil - Sta Maria $-\mathrm{RS}$

Giraffa, L. M. M.; Mora, M. C. (2013). Evasão na Disciplina de Algoritmo e Programação: Um Estudo a Partir dos Fatores Intervenientes na Perspectiva do Aluno. In: III Conferencia Sobre el Abandono en la Educación Superior (Iii Clabes), v. 3, 2013, Espanha.

Giraffa, L. M. M.; Muller L; Moraes, M. C. (2015). Ensinado Programação apoiada por um ambiente virtual e exercícios associados a cotidiano dos alunos: compartilhando alternativas e lições aprendidas. In $4^{\circ}$ Congresso Brasileiro de Informática na Educação (CBIE), I Workshop de Ensino em Pensamento Computacional, Algoritmos e Programação (WAlgProg). Maceió, Brasil.

Petry, P. G. (2005). Um Sistema Para o Ensino e Aprendizagem de Algoritmos Utilizando um Companheiro de Aprendizagem Colaborativo. Florianópolis, SC: UFSC, 2005. Originalmente apresentada como dissertação de mestrado, Universidade Federal de Santa Catarina.

Rapkiewicz, E. C.; Falkembach G.; Seixas L.; Rosa, N. S.; Cunha, V. V.; Klemann, M. (2006). Estratégias Pedagógicas no Ensino de Algoritmos e Programação Associadas ao Uso de Jogos Educacionais. Revista Renote - Novas Tecnologias na Educação, v.4, n.2, p. 1-11.

Sousa, S. de O. (2011) Aprendizagem Baseada em Problemas (PBL- Problem-based Learning): Estratégia para o Ensino e Aprendizagem de Algoritmos e Conteúdos Computacionais. Presidente Prudente, SP: UEP, 2011. Originalmente apresentada como dissertação de mestrado, Universidade Estadual Paulista.

Timmermann, G. L. K. (2015). O Desafio de Aprender e Ensinar Algoritmos: Mediações que Professores e Alunos Estabelecem com o Conteúdo no Ensino Superior. Ijuí, RS: UNIJUÍ, 2015. Originalmente apresentada como dissertação de mestrado, Universidade Regional do Noroeste do Estado do Rio Grande do Sul.

Vieira, E. C.; Lima Junior, A. T. de; Vieira, P. de P. V.(2015). Dificuldades no Processo de Aprendizagem de Algoritmos: uma Análise dos Resultados na Disciplina de AL1 do Curso de Sistemas de Informação da FAETERJ. Paracambi, v. 10, n.1, p.1- 15. 